\title{
Correlation of morphological profile and receptor status in breast carcinoma: An institutional study in tertiary care hospital
}

\author{
Authors \\ Dr Anup Kumar ${ }^{1}$, Dr Deergha Singh $^{2}$, Dr M.L.Gupta ${ }^{3}$ \\ ${ }^{1}$ Department of Pathology, RDBP Jaipuria Hospital, Jaipur, Rajasthan, India \\ ${ }^{2,3}$ Department of Pathology, Geetanjali Medical College and Hospital, Udaipur, Rajasthan, India
}

\begin{abstract}
Background: Receptor status assessment is not routinely carried out in patients of breast cancer in the Indian subcontinent. Limited data is available on histological and receptor status in Indian patients. In this study receptor status has been correlated with morphological prognostic parameters.

Objective: To analyze receptor status and its correlation with morphological prognostic parameters in Indian females.

Methods: 50 mastectomy specimens of breast carcinoma were received in the department of pathology at Geetanjali medical college and hospital, Udaipur, Rajasthan, India. All the 50 cases were subjected for ER, PR, HER 2 Neu receptor study.

Result: $64 \%$ patients diagnosed with breast cancer were 50 years or younger in age. $94 \%$ patients were diagnosed as Invasive ductal carcinoma whereas $6 \%$ patients were diagnosed with tubular and tubulobular carcinoma. Only 4\% cases were ER/ PR/ HER 2 Neu positive and $16 \%$ cases were triple negative indicating poor prognosis.
\end{abstract}

Keywords: Breast cancer, Invasive ductal carcinoma (IDC), Estrogen Receptor, Progesterone Receptor, Her 2 Neu Receptor.

\section{Introduction}

Breast cancer is a heterogeneous entity constituting a varied spectrum of clinico-pathological and molecular features associated with different therapeutic and prognostic outcomes ${ }^{[1]}$. Breast carcinoma is the most common malignant tumor being the leading cause of death amongst women resulting in more than $1,000,000$ cases worldwide annually ${ }^{[2]}$. According to WHO, India has a cancer mortality rate of 79 per 100,000 deaths and accounts for over 6 percent of total deaths ${ }^{[3]}$. The management and prognosis of breast cancer is influenced by various parameters such as histological grading and type, stage, tumor size, lymph node status, lymphovascular invasion and receptor status of estrogen (ER), progesterone (PR) and HER2 Neu over expression ${ }^{[4]}$. There has been realization that the presence of ER/PR receptor in tumor tissue has a strong correlation with response to hormonal therapy ${ }^{[5]}$. In recent times, hormonal status determination on biopsy specimen has been advocated as a standard practice ${ }^{[6]}$. The hormone receptors play an essential role in the development, therapeutic and progression of the disease along with identification of patients with lower risk of relapse ${ }^{[7]}$. Breast cancer survival rate is closely related to early detection, appropriate management, genetic predisposition and hormone receptor status. 


\section{Material \& Methods}

A cross sectional study was conducted in the department of Pathology from 2016 to 2019 at Geetanjali Medical College \& Hospital, Udaipur, Rajasthan, India. A total of 50 patients were included in the study. Relevant clinical details were obtained. All the specimens received were subjected to routine histopathological as well as immunohistochemical analysis.

The specimens were routinely fixed overnight in $10 \%$ neutral buffered formalin. The representative sections were submitted the next day according to the standard grossing protocol and subsequently processed. The sections were then stained with routine hematoxylin and eosin $(\mathrm{H} \& \mathrm{E})$ stain. The sections were first diagnosed on the basis of WHO classification and histological grading was done according to Modified Bloom Richardson grading system. The suitable blocks were selected for Immunohistochemistry and were subjected to ER, PR, HER 2 Neu receptor study.

\section{Results}

A total of 50 cases were included in the present study. Of all the female patients, the youngest patient was 26 years old and the oldest patient was 82 years old. Majority of the cases were in the age group of 41-60 years with the mean age at 52.18 years. (Table-1)

Table 1 Age distribution of cases

\begin{tabular}{|l|c|c|}
\hline Age in years & Frequency & Percent \\
\hline $21-40$ & 12 & $24 \%$ \\
\hline $41-60$ & 24 & $48 \%$ \\
\hline $61-80$ & 13 & $26 \%$ \\
\hline $81 \&$ Above & 01 & $02 \%$ \\
\hline TOTAL & 50 & $100 \%$ \\
\hline
\end{tabular}

In terms of side of involvement, left side of the breast was affected more i.e.26 (52\%) as compared to the right side which consisted of 24 (48\%) cases. All the 50 patients had undergone MRM. (Table -2)

Table 2 Sidewise distribution of breast carcinoma.

\begin{tabular}{|l|c|c|}
\hline Side & Frequency & Percent \\
\hline Right & 24 & $48 \%$ \\
\hline Left & 26 & $52 \%$ \\
\hline
\end{tabular}

Majority of the cases had tumor size more than $2 \mathrm{~cm}$ comprising of 34 cases (68\%) and the remaining 16 cases $(32 \%)$ had tumor size less than $2 \mathrm{~cm}$. (Table 3)

Table 3 Size of Tumor

\begin{tabular}{|l|c|c|}
\hline Tumor Size & Frequency & Percentage \\
\hline$\leq \mathbf{2} \mathbf{~ c m}$ & 16 & $32 \%$ \\
\hline$>\mathbf{2} \mathbf{~ c m}$ & 34 & $68 \%$ \\
\hline
\end{tabular}

Infiltrating ductal carcinoma (IDC) was the predominant morphological category with IDC NOS (Not otherwise specified) in $46(92 \%)$ cases. 2 cases had Tubulobular carcinoma (4\%), one cases $(2 \%)$ invasive lobular carcinoma and 1 case of Tubular carcinoma (2\%). (Table - 4)

Table 4 Histological subtypes of breast carcinoma

\begin{tabular}{|l|c|c|}
\hline \multicolumn{1}{|c|}{ Histological subtypes } & Frequency & Percentage \\
\hline IDC( NOS) & $\mathbf{4 6}$ & $\mathbf{9 2 \%}$ \\
\hline Tubulobular carcinoma & $\mathbf{0 2}$ & $\mathbf{0 4 \%}$ \\
\hline Invasive lobular carcinoma & $\mathbf{0 1}$ & $\mathbf{0 2} \%$ \\
\hline Tubular carcinoma & $\mathbf{0 1}$ & $\mathbf{0 2 \%}$ \\
\hline
\end{tabular}

Lymph node metastasis was found to be positive in 32 cases $(64 \%)$ and negative in 18 cases (36\%). Out of 32 cases of positive lymph node metastasis, involvement of more than 4 lymph nodes was observed in 9 cases only $(39.1 \%)$ whereas involvement of less than 4 lymph nodes was seen in majority of cases i.e. 23 cases accounting for $71.8 \%$ and only one case showed perineural invasion.

On the correlation of grade with hormonal receptor status, In case of Grade I tumors, $2(50 \%)$ cases exhibited triple negative expression while 1 (25\%) case showed triple positivity and only $1(25 \%)$ case with ER-/PR+/HER2- expression was reported. Amongst the Grade II tumors, Majority of the grade II tumors showed ER-/PR-/HER2+ expression which was noted in 18(41.86\%) cases. 9(20.93\%) cases showed ER-/PR+/HER2- expression followed by $5(11.62 \%)$ cases showing triple negative expression. ER-/PR+/HER2- expression was also seen in five $(11.62 \%)$ cases whereas ER+/PR/HER2- expression was noted in 3(6.97\%) cases. ER-/PR+/HER2+ expression was observed in 2 $(4.65 \%)$ cases along with $1(2.32 \%)$ case showing triple positivity In case of Grade III tumors, $\mathrm{ER} / \mathrm{PR}+/ \mathrm{HER} 2-$ expression was noted in $2(66.6 \%)$ 
cases while triple negativity was observed in only $1(33.3 \%)$ case. Table -5

Table 5 Correlation of grade with hormonal receptor status

\begin{tabular}{|l|c|c|c|c|}
\hline $\begin{array}{l}\text { Hormone } \\
\text { Receptors }\end{array}$ & N & Grade I & Grade II & Grade III \\
\hline ER+/PR+/HER 2+ & $\mathbf{2}$ & $01(25 \%)$ & $01(2.32 \%)$ & NIL \\
\hline ER+/PR-/HER2- & $\mathbf{3}$ & NIL & $03(6.97 \%)$ & NIL \\
\hline ER-/PR+/HER2- & $\mathbf{6}$ & $01(25 \%)$ & $05(11.62 \%)$ & NIL \\
\hline ER-/PR+/HER2+ & $\mathbf{2}$ & NIL & $02(4.65 \%)$ & NIL \\
\hline ER-/PR+/HER2- & $\mathbf{1 1}$ & NIL & $09(20.93 \%)$ & $02(66.6 \%)$ \\
\hline ER-/PR-/HER2+ & $\mathbf{1 8}$ & NIL & $18(41.86 \%)$ & NIL \\
\hline ER-/PR-/HER 2- & $\mathbf{8}$ & $02(50 \%)$ & $05(11.62 \%)$ & $01(33.3 \%)$ \\
\hline Total & & $\mathbf{0 4}$ & $\mathbf{4 3}$ & $\mathbf{0 3}$ \\
\hline
\end{tabular}

\section{Discussion}

It is well known that breast cancer prognosis depends on various clinicopathological factors including tumor size, tumor grade, hormone receptor status, HER-2 status and metastatic status of lymph nodes ${ }^{[6,8]}$.

Age range among Indian breast cancer patients is found to be lower when compared to the Western countries with an average difference of one decade. This is likely to be due to the different age distribution of the Indian population, where only $7 \%$ of the population is above the age of 60 years ${ }^{[9-16]}$.

In the present study $48 \%$ of women were in the age group of 41-60 years, in contrast a study by Pakseresht et $a l^{[9]}$ had age range lower than 40 years $(34.8 \%)$, whereas Ambroise et al ${ }^{[13]}(46.4 \%)$ Suvarchala et $a l^{[11]}(45.31 \%)$, and Rhodes et $a l^{[17]}$ $(36.42 \%)$ had higher age range between 51-60years.

Literature search reveals breast carcinomas are more common in the left breast than the right. The possible explanations are that, the left breast being more bulky and having larger volume of breast tissue comparatively. However side of breast involved has no clinical significance ${ }^{[10,18]}$. In the present study left breast were marginally more affected than right.

In terms of size of the tumor, majority of the cases had tumor size more than $2 \mathrm{~cm}$ constituting $68 \%$ cases and the remaining $32 \%$ cases had tumor size less than $2 \mathrm{~cm}$. Similarly, Lokuhetty et al reported $58 \%$ cases with tumor size more than $2 \mathrm{~cm}^{[19]}$. The study conducted by Lakmini KB. Mudduwa et al reported $85.5 \%$ cases having tumor size greater than
$2 \mathrm{~cm}$ while only $14.5 \%$ of tumors measured less than $2 \mathrm{~cm}^{[20]}$.

Invasive Ductal carcinoma was the most common histological type with Invasive Ductal carcinoma (NOS) comprising of $76 \%$ of all the cases of breast carcinoma. Puvitha et al ${ }^{[21]}$ reported $79 \%$ cases of IDC (NOS) which is similar to our study. Sofi et al [22] findings consisted of $80.30 \%$ cases of IDC (NOS).

Lymph node metastasis was found to be positive in $64 \%$ of all the cases and negative in $36 \%$ in our study. Lobna Ayadi et al ${ }^{[23]}$ reported $65 \%$ cases to be positive for lymph node metastasis which is in concordance to our findings. Zubair Ahmed et al ${ }^{\text {[24] }}$ also reported $74.77 \%$ cases to be positive for lymph node metastasis.

In our study, most of the tumors were mostly Grade II tumors accounting for $86 \%$ of cases followed by grade III $(08 \%)$ tumor and grade II $(04 \%)$ tumor. In study conducted by Pathak TB et al ${ }^{[25]}$ grade II (59\%) tumor was the commonest. Zubair Ahmed et $\mathrm{al}^{[24]}$ reported grade II $(75.83 \%)$ as the commonest followed by grade III (20\%) and grade I (4.17\%).

The hormone receptor status is a prognostic marker of outmost importance. It is also helpful in determination of the appropriate treatment modality in the treatment of breast cancer.

In our study, IHC for ER, PR and HER2 Neu status was performed on appropriate tissue sections. The findings revealed that $36 \%$ patients were ER positive while $64 \%$ were negative. Desai SB et al ${ }^{[26]}$ conducted a similar study in which ER positivity was observed in $32.6 \%$ cases which is similar to our findings in context of ER positive breast carcinoma patients. Priti lal et $\mathrm{al}^{[27]}$ observed that $71.6 \%$ cases were positive for ER. In case of PR receptor status, $42 \%$ cases were PR positive and $58 \%$ were reported to be negative. Rao et al ${ }^{[28]}$ observed that $31.7 \%$ cases showed PR positivity. HER 2 Neu expression was seen in $44 \%$ of cases which is in correlation with the study conducted by Puvitha et $\mathrm{al}^{[21]}$ where HER 2 Neu expression was observed in $48.4 \%$ cases. Dutta $\mathrm{V}$ et $\mathrm{al}^{[29]}$ also conducted a similar study in which HER 2 Neu overexpression was seen in $57.2 \%$ cases. In our study, only 2 cases 
(04\%) were triple positive whereas only $8(16 \%)$ cases exhibited triple negativity. Aye Thike et al ${ }^{[30]}$ reported $13 \%$ cases as triple negative breast cancer which is similar to our findings.

Puvitha et al showed triple positive breast cancer in $6 \%$ of patients in their study which is also similar to our findings.

\section{Conclusion}

In the study conducted above, majority of the cases $(48 \%)$ were in the age group of 41-60 years.

Infiltrating Ductal Carcinoma (NOS) was the most common breast cancer encountered in our institute with majority of the tumors falling in the category of Grade II tumors. Lymph node metastasis, tumor size more than $2 \mathrm{~cm}$ were seen in majority of the tumors. Only $4 \%$ cases were ER/PR and HER 2 Neu positive while $16 \%$ cases were triple negative breast carcinoma indicating poor prognosis.

\section{References}

1. Yersal O, Barutca S. Biological subtypes of breast cancer: Prognostic and therapeutic implications. World J Clin Oncol.2014; 5(3): 412-424.

2. Makki. Diversity of Breast Carcinoma: Histological Subtypes and Clinical Relevance. Clinical Medicine Insights. Pathology.2015;8 :23-31.

3. Rajpal S, Kumar A, Joe W. Economic burden of cancer in India: Evidence from crosssectional nationally representative household survey- 2014. PLoS ONE .2018;13(2):1-17.

4. Thiygarajan M, Navrathan N, Mohanapriya T, Kumar A, Singh B. Correlation between estrogen receptor, progesterone receptor, HER-2/neu and other prognostic factors in carcinoma breast in Indian population. Int Surg J. 2015; 2:515-22.

5. Gupta D, Gupta V, Marwah N, Gill M, Gupta S, Gupta G et al. Correlation of Hormone Receptor Expression with Histologic Parameters in benign and malignant breast tumors. Iranian Journal of Pathology.2015;10 (1): $23-34$.
6. Omranipour $\mathrm{R}$, Alipour $\mathrm{S}$, Hadji $\mathrm{M}$, Fereidooni F, Jahanzad I, Bagheri K. Accuracy of Estrogen and Progesterone Receptor Assessment in Core Needle Biopsy Specimens of Breast Cancer. IRCMJ. 2013 June; 15(6): 515-8.

7. Louie M.C, Sevigny M.B. Steroid hormone receptors as prognostic markers in breast cancer. Am J Cancer Res .2017;7(8):16171636.

8. Geethamala K et al. Histopathological Grade versus Hormone Receptor Status in Breast Carcinoma- Treasure The Past. International Journal of Biomedical Research .2015; 6(07): 466-471.

9. Pakseresht $\mathrm{S}$, Ingle $\mathrm{G} \mathrm{K}$, Bahadur $\mathrm{A} \mathrm{K}$, Ramteke V K, Singh M M, Garg S, Agarwal P N. Risk factors with breast cancer among women in Delhi. Indian J Cancer. 2009; 46:132-8.

10. Azizun-Nisa, Bhurgri Y, Raza F, Kayani N. Comparison of ER, PR and HER-2/neu (C-erb B 2) reactivity pattern with histologic grade, tumor size and lymph node status in breast cancer. Asian Pac J Cancer Prev .2008; 9:5536.

11. Suvarchala SB, Nageshwararao R. Carcinoma Breast-Histopathological and hormone receptors correlation. J Biosci Tech.2011:2; 340-48.

12. Ghosh J, Gupta S, Desai S, Shet T, Radhakrishnan S, Suryavanshi $\mathrm{P}$ et al. Estrogen, progesterone and HER2 receptor expression in breast tumors of patients, and their usage of HER2-targeted therapy, in a tertiary care centre in India. Indian $\mathrm{J}$ Cance. 2011;48:391-6

13. Ambroise M, Ghosh M, Mallikarjuna VS, Kurian A. Immunohistochemical Profile of Breast Cancer Patients at a Tertiary Care Hospital in South India Immunohistochemical Profile of Breast Cancer Patients at a Tertiary Care Hospital in South India. Asian Pacific Journal of Cancer Prevention. 2011;12:625629. 
14. Shet T, Agrawal A, Nadkarni M, Palkar M, Havaldar R, Parmar V, et al. Hormone receptors over the last 8 years in a cancer referral centre in India: What was and what is. Indian J Pathol Microbiol.2009; 50:284-90.

15. Murthy N S, Chaudhry K, Nadayil D, Agarwal U K, Saxena S. Changing trends in incidence of breast cancer: Indian scenario. Indian $\mathrm{J}$ Cancer.2009; 46:73.

16. Nandakumar A, Ramnath T, Chaturvedi M. The magnitude of cancer breast in India: a summary. Indian J Surg Oncol. 2010; 1:8-9.

17. Rhodes A, Jasani B, Balaton AJ, Barnes DM, Miller KD. Frequency of oestrogen and progesterone receptor positivity by immunohistochemical analysis in 7016 breast carcinomas: correlation with patient age, assay sensitivity, threshold value, and mammographic screening. J Clin Pathol. 2000; 53: 688-96.

18. Sandhu DS, Sandhu S, Karwasra RK, Marwah S. Profile of breast cancer patients at a tertiary care hospital in north India. Indian $\mathrm{J}$ Cancer .2010; 47:16-22.

19. Lokuhetty MDS, Ranaweera GG, Wijeratne MD, Sheriffdeen SH. Profile of breast cancer in a group of women in a developing country in South Asia: is there a difference? World $\mathbf{J}$ Surg. 2009 Mar;33(3):455-9.

20. Lakmini KB. Mudduwa. Quick score of hormone receptor status of breast carcinoma: correlation with the other clinico-pathological prognostic parameters. Indian J Pathol Microbiol. 2009; 52:159-63.

21. Puvitha R D, S Shifa. Breast Carcinoma, Receptor Status, and Her2 neu Overexpression Revisited. International Journal of Scientific Study, 2016 Jan;3(10); 52-58.

22. Sofi GN, Nabi J, Nadeem R, Shiekh RY, Khan FA, Sofi AA, et al. Estrogen receptor and progesterone receptor status in breast cancer in relation to age, histological grade, size of lesion and lymph node involvement. Asian Pacific J Cancer Prev 2012;13:5047-5052.
23. Lobna Ayadi, Abdelmajid Khabir, Habib Amouri, Sondes Karray, Abdallah Dammak, Mohamed Guermazi, et al. Correlation of HER-2 overexpression with clinicopathological parameters in Tunisian breast carcinoma. World J Surg Oncol. 2008;6:112.

24. Zubair Ahmad, Amna Khurshid, Asim Qureshi, Romana Idress, Nasira Asghar, Naila Kayani. Breast carcinoma grading, estimation of tumor size, axillary lymph node status, staging, and Nottingham prognostic index scoring on mastectomy specimens. Indian $\mathrm{J}$ Pathol Microbiol. 2009;52:477-81.

25. Pathak TB, Bashyal R, Pun CB, Shreastha S, Bastola S, Neupane $S$, et al. Estrogen and Progesterone receptor expression in breast carcinoma. Journal of Pathology of Nepal 2011;1:100-103.

26. Desai SB, Moonim MT, Gill AK, Punia RS, Naresh KN, Chinoy RF et al. Hormone receptor status of breast cancer in India: a study of 798 tumours. The Breast. 2000 Oct; 9(5):267-70.

27. Priti Lal, Lee K. Tan, Beiyun Chen. Correlation of HER2 Status with Estrogen and Progesterone Receptors and Histologic Features in 3,655 Invasive Breast Carcinomas. Am J Clin Pathol . 2005;123:541-46.

28. Rao C, Shetty J, Prasad HL. Study of morphological profile and receptor status in breast carcinoma. Journal of Cancer Research and Therapeutics . 201;:9(1):44-49.

29. Dutta V, Chopra GS, Sahai K, Nema SK. Hormone Receptors, Her-2/Neu and chromosomal Aberrations in Breast Cancer. MJAFI. 2008;64:11-15.

30. Thike AA, Cheok PY, Jara-Lazaro AR, Tan B, Tan P, Tan PH. Triple-negative breast cancer: clinicopathological characteristics and relationship with basal-like breast cancer. Mod Pathol. 2010 Jan;23(1):123-33. 